\title{
Erratum to: Mentored Discussions of Teaching: An Introductory Teaching Development Program for Future STEM Faculty
}

\author{
Rachael R. Baiduc ${ }^{1} \cdot$ Robert A. Linsenmeier $^{2}$. \\ Nancy Ruggeri ${ }^{1}$
}

Published online: 29 December 2015

(C) Springer Science+Business Media New York 2015

Erratum to: Innov High Educ (2015)

DOI 10.1007/s10755-015-9348-1

The authors regret that acknowledgement of their funding source was omitted from the manuscript. This work was supported by National Science Foundation grant number DUE-1231286.

The online version of the original article can be found at http://dx.doi.org/10.1007/s10755-015-9348-1

\section{Rachael R. Baiduc}

RRBaiduc@northwestern.edu

1 Searle Center for Advancing Learning and Teaching, Northwestern University, Evanston, IL, USA

2 Northwestern University, Evanston, IL, USA 